\title{
Behavioral interference and C/EBP $\beta$ expression in the insular-cortex reveal a prolonged time period for taste memory consolidation
}

\author{
Maayan Merhav, ${ }^{1}$ Shelly Kuulmann-Vander, ${ }^{1}$ Alina Elkobi, Shlomit Jacobson-Pick, \\ Avi Karni, and Kobi Rosenblum² \\ Department for Neurobiology and Ethology, Center for Brain and Behavior, University of Haifa, Haifa 31905, Israel
}

\begin{abstract}
Memory consolidation is defined as the time window during which the memory trace is susceptible to behavioral, electrical, or pharmacological interventions. Here, we presented rats with two novel tastes at consecutive time intervals. Clear interference was evident when a novel taste formed the second taste input whereby, surprisingly, the time window for interference was found to last more than $10 \mathrm{~h}$. In addition, we detected an increase of C/EBP $\beta$ protein expression in the gustatory cortex $18 \mathrm{~h}$ after novel taste learning. This modulation was attenuated by a subsequent novel taste. Our findings reveal temporal constraints and a lingering nature of taste memory consolidation.
\end{abstract}

Memory consolidation, the transformation of short- into longterm memory, is characterized by a time interval following acquisition, during which the novel experience remains labile and highly sensitive to biochemical, pharmacological, physical, or behavioral manipulations. It has been argued that memory consolidation can be conceptualized as consisting of two major processes: system and cellular consolidation. The time window of cellular consolidation is estimated in hours, its main feature being its sensitivity to protein synthesis inhibitors (Davis and Squire 1984; Alberini 1999; Dudai 2004). In this study, using novel taste learning and latent inhibition (LI) of conditioned taste aversion (CTA) as our model behavioral system, we explored the time-course of memory consolidation. Both taste learning and taste memory are robust phenomena and can be tested in a quantitative manner within the context of CTA, i.e., LI (Arwas et al. 1989). LI, in combination with CTA, can be used to assess the familiarity of a given taste and represents a behavioral paradigm by which unimodal incidental learning can be analyzed (Rosenblum et al. 1993, 1995, 1996; Gallo et al. 1998; Miranda et al. 2000; Ferreira et al. 2002; Belelovsky et al. 2005). The time window for taste memory consolidation can be defined by using different types of interference, including behavioral distracters (conflicting experience), seizure, anatomical lesions, and pharmacological agents such as protein synthesis inhibitors (Wixted 2004). Indeed, taste memory consolidation, as all memory systems studied so far, is sensitive to protein synthesis inhibitors applied before or immediately after learning (Rosenblum et al. 1993; Meiri and Rosenblum 1998; Houpt and Berlin 1999).

We investigated the temporal window of novel taste memory consolidation by applying a new behavioral paradigm and brain biochemistry in the rat. Specifically, we set out to define the time window of susceptibility to interference by means of a second novel taste as a distracter. In addition, we measured $\mathrm{C} / \mathrm{EBP} \beta$ expression in the taste cortex as a delayed correlative biochemical event for taste memory consolidation. The behavioral and biochemical experiments suggest that taste memory

\footnotetext{
${ }^{1}$ These authors contributed equally to this work.

${ }^{2}$ Corresponding author.

E-mail kobir@psy.haifa.ac.il; fax 972-4-8249654.

Article published online before print. Article and publication date are at http:// www.learnmem.org/cgi/doi/10.1101/lm.282406.
}

consolidation continues for $>10 \mathrm{~h}$ after the termination of the learning experience. This time frame expands the time window suggested previously in studies using protein synthesis or MAPK inhibitors (Rosenblum et al. 1993; Berman et al. 1998; Belelovsky et al. 2005). In addition, our results suggest that the biochemical manifestation of learning a novel taste is different from the retention and relearning of a known taste.

The subjects were adult male Sprague-Dawley rats, weighing 150-174 g; supplied by Harlan; and caged individually on a 12-h light/12-h dark cycle with water and laboratory rodent chow ad libitum unless otherwise indicated. All the experiments were done in adherence to the guidelines of National Institutes of Health (NIH) and Haifa University's Ethical Committee.

Saccharin $(0.1 \%)$ or $\mathrm{NaCl}(0.3 \%)$ were used as a novel taste and $\mathrm{LiCl}(0.15 \mathrm{M}, 2 \%$ body weight) as a toxic agent. CTA was performed as previously described (Rosenblum et al. 1993). The three behavioral paradigms are described in Table 1; each column refers to a day.

For the biochemical analysis, different rats were decapitated at different time points following the behavioral procedures as indicated below. In the experimental group, rats were introduced to $0.1 \%$ saccharin, ad libitum from two pipettes of $10 \mathrm{~mL}$ water each. In the control group, rats received tap water ad libitum from two pipettes of $10 \mathrm{~mL}$ water each. The insular cortex was dissected out by using the crossing of the rhinal fissure and the medial cerebral artery as a reference point (Rosenblum et al. 1995). The tissue was immediately homogenized in a glass Teflon homogenizer in $300 \mu \mathrm{L}$ of SDS sample buffer and boiled for 5 min. Samples were then stored at $-20^{\circ} \mathrm{C}$ until further usage.

For Western blot analysis, the same amounts of samples in SDS sample buffer were subjected to SDS-PAGE, blotted, and reacted with antibodies as described before (Rosenblum et al. 1996).

The following reagents were used for the biochemical analysis. C/EBP $\beta$ (1:1000) polyclonal antibody and $\beta$ Actin (1:2000) polyclonal antibody were obtained from Santa Cruz Biotechnology. Goat anti-rabbit (IgG) HRP conjugated and rabbit anti-goat (IgG) HRP conjugated $(1: 20,000)$ were purchased from Chemicon. An Enhanced chemiluminescense (ECL+) kit was purchased from Amersham. All other chemicals were of the highest analytical grade available.

For the statistical analysis, differences among the groups of the behavioral experiments were determined by using one-way 
Table 1. Taste learning paradigms

\begin{tabular}{|c|c|c|c|c|c|c|c|c|c|}
\hline Conditioned taste aversion & WD & WD & WD & CTA & WD & WD & Test & & \\
\hline Latent inhibition & WD & WD & WD & $\mathrm{LI}$ & WD & WD & CTA & WD & WD \\
\hline Interference to LI & WD & WD & WD & $\begin{array}{l}\mathrm{LI}>\text { Interference } \\
\text { or } \\
\text { Interference > LI }\end{array}$ & WD & WD & CTA & WD & WD \\
\hline
\end{tabular}

WD (water deprivation): Rats were habituated to consume a daily water amount, during 20 min a day, from two pipettes, each containing $10 \mathrm{~mL}$ tap water.

CTA: $20 \mathrm{~mL}$ of novel taste was given; rats were allowed to consume the novel taste during $20 \mathrm{~min}$. LiCl was injected $1 \mathrm{~h}$ later (intraperitoneally). $\mathrm{LI}$ (LI to CTA): A $10 \mathrm{~mL}$ amount of the novel taste used in conditioning was given; the daily liquids ratio was completed (up to $20 \mathrm{~mL}$ ) by tap water, several hours later.

Interference: At time point $\mathrm{x}$, before or after the pre-exposure to $10 \mathrm{~mL}$ of the novel taste (i.e., the $\mathrm{LI}), 10 \mathrm{~mL}$ of another novel taste was given.

Test: Rats were subjected simultaneously to eight pipettes, four containing $3 \mathrm{~mL}$ of the target taste and four containing $3 \mathrm{~mL}$ of water. Rats were allowed to drink for $20 \mathrm{~min}$. The aversion index was defined as [ $\mathrm{mL}$ water $/(\mathrm{mL}$ water $+\mathrm{mL}$ novel taste $) \times 100]$ consumed in the test; whereby the chance level was $50 \%$, while the higher the aversion index, the more the rats preferred water to novel taste.

ANOVA. For post hoc comparisons, least significant difference (LSD) contrast test was used with $\alpha$ level of 0.05 . Differences among biochemical experiments were determined by using twotailed Student's $t$-test. Results are presented as mean \pm SEM.

We hypothesized that while the taste cortex is engaged in the consolidation of one taste input, an intensive input of a second novel taste may attenuate the consolidation of the first one. To that end, we used the LI protocol as described above with one modification: At pre-exposure stage, the animals were presented to taste A (10 mL of $0.1 \%$ saccharin) and at a certain time point later to taste $\mathrm{B}(10 \mathrm{~mL}$ of $0.3 \% \mathrm{NaCl})$. The CTA and test were performed to taste A (saccharin) (Fig. 1A).

Animals that had been pre-exposed to $10 \mathrm{~mL}$ saccharin (as a novel taste) and $5 \mathrm{~min}$ or $5 \mathrm{~h}$ later were exposed to $10 \mathrm{~mL}$ of $\mathrm{NaCl}$ had no memory for the saccharin pre-exposure (Fig. 1B). The aversion indices of these animals (93\% and 90\% for $5 \mathrm{~min}$ and 5 $\mathrm{h}$, respectively) are similar to the CTA animals (90\%) and statistically different from the LI $10 \mathrm{~mL}$ group $(74 \%, P<0.01)$. The results suggest that a memory for a given taste is attenuated when a different unimodal taste input is presented $5 \mathrm{~min}$ or $5 \mathrm{~h}$ later, i.e., the existence of anterograde interference by the second taste $(\mathrm{NaCl})$ on the saccharin taste memory. To define the temporal profile of taste memory consolidation, similar interference experiments with time intervals of 10 or $20 \mathrm{~h}$ were used (Fig. $1 \mathrm{~A}, \mathrm{~B}$ ). To our surprise, the interference was still effective at a time interval of $10 \mathrm{~h}$ between the two tastes' inputs. The aversion index $(86 \%)$ is similar to the one obtained in the CTA group (90\%) and different from the one in the LI 10-mL group $\left(74 \%, F_{(5,53)}=11.561\right.$, $P<0.01)$ (Fig. 1B). There was no interference when the time interval between the two tastes' inputs was $20 \mathrm{~h}(81 \%)$.

Following the identification of the time frame for anterograde interference, we tested the possibility for retrograde interference at similar time intervals (i.e., the ability of the first taste to block the consolidation of the second one). In these experiments, the order of the two tastes was inverted. We first presented the animals with $10 \mathrm{~mL}$ of $\mathrm{NaCl}$, and at a later time point, the animals consumed $10 \mathrm{~mL}$ of saccharin. The CTA and LI test were done with saccharin (Fig. 1C). The rats that were preexposed to saccharin, $5 \mathrm{~min}$ after consumption of $10 \mathrm{~mL} \mathrm{NaCl}$, showed an aversion index (76\%) that is similar to the one obtained in the LI $10-\mathrm{mL}$ saccharin group (74\%). Therefore, the memory for the saccharin pre-exposure was not affected. Both groups were statistically different from the CTA group $(90 \%$, $F_{(3,40)}=20.088, P<0.01$ ) (Fig. 1C). Similar to the 5-min interval, larger time intervals were ineffective to reduce the amount of taste memory in the retrograde paradigms (77\% and $80 \%$ for $5 \mathrm{~h}$ and $10 \mathrm{~h}$, respectively).

These results suggest that rats remember the last novel taste they consume and that taste memory consolidation extends for over $>10 \mathrm{~h}$ following the novel taste experience.
A familiar taste is different from a known taste in many perspectives, including biochemical correlates in the taste cortex (Rosenblum et al. 1997). To test whether a previously known taste induces taste interference to a similar degree that a novel taste does, we applied the 5-h interference protocol with one modification (Fig. 1D): The interfering taste, $\mathrm{NaCl} 0.3 \%$, was made familiar to the rats (i.e., the rats had consumed it for three consecutive days before the interference experiments). No interference was observed when the interfering taste was a familiar one (Fig. 1E). The aversion index was different both from the interference of the novel taste group and the CTA group (68\% vs. $90 \%$ and $90 \%$, respectively, $F_{(3,42)}=16.071, P<0.01$ ) but not different from the LI $10 \mathrm{~mL}$ group (74\%). We concluded that the process of learning, but not retrieving new taste information, occupies the taste system in such a way that it disrupts the consolidation of former knowledge and induces the anterograde interference.

The biochemical correlates of a given learning experience, as well as the time window of effectiveness of local application of different inhibitors in the taste cortex, are on a time scale of minutes to $1 \mathrm{~h}$ following training (Rosenblum et al. 1993, 1995, 1997; Berman et al. 1998; Ferreira et al. 2002; Miranda and McGaugh 2004). However, given the above behavioral results, we tested the temporal profile of C/EBP $\beta$ 's expression in the taste cortex after novel taste consumption. C/EBP $\beta$ is a protein previously found to be expressed on a time scale of many hours following a learning experiences in other brain structures (Taubenfeld et al. 2001). The expression of C/EBP $\beta$ was analyzed, in relation to ßactin's expression within the same sample, in the insular cortex of the rats, following different time intervals, subsequent to novel taste (saccharin) or familiar taste (water) consumption. C/EBP $\beta$ 's expression was clearly induced at $18 \mathrm{~h}$ following the consumption of $10 \mathrm{~mL}$ of a novel taste $(1.417 \pm 0.107$; $n=5$ in novel taste group; $0.913 \pm 0.054 ; n=5$ in familiar taste group; $t$-test: $\left.t_{(10)}=-3.366, P<0.01\right)$, but not in any other timepoint tested (20, $30 \mathrm{~min}, 3,6,14$ or $24 \mathrm{~h}$ ) (Fig. 2).

The expression of $\mathrm{C} / \mathrm{EBP} \beta$ in the insular cortex of animals that experienced interference protocol was tested. The hypothesis was that given that C/EBP $\beta$ 's expression is a correlate of novel taste memory consolidation, under conditions of interference the expression of $\mathrm{C} / \mathrm{EBP} \beta$ will be attenuated. The results show (Fig. 3) that consuming $10 \mathrm{~mL}$ of taste B (novel taste) $4 \mathrm{~h}$ after taste A significantly reduced C/EBP $\beta$ 's expression in comparison to the control group $(0.877 \pm 0.040 n=9$ in test group; $1.001 \pm 0.038 n=10$ in control group; $t$-test: $t_{(17)}=-2.230$, $P<0.05)$. Thus, C/EBPß's induction in the insular cortex was correlated with the behavioral measure for memory formation and could be interfered with in a similar way to behavior.

How long does the process of taste memory consolidation take? In the past it was shown that pharmacological agents

\section{Learning \& Memory \\ www.learnmem.org}


blocked specifically taste memory consolidation and not learning (Rosenblum et al. 1993; Houpt and Berlin 1999). The time frame during which the pharmacological agents were able to block memory consolidation was in the range of minutes following learning and is comparable with other learning paradigms (for review, see Davis and Squire 1984; Rosenblum et al. 1993; Berman et al. 1998). Here, we used another second taste input and measured its ability to interfere with memory consolidation. These experiments were similar to the ones used in other learning paradigms. For example, in motor skill learning in humans (Goedert 2002) and in visual displacement in monkeys (Flook and McGonigle 1977), memory consolidation was disrupted by a

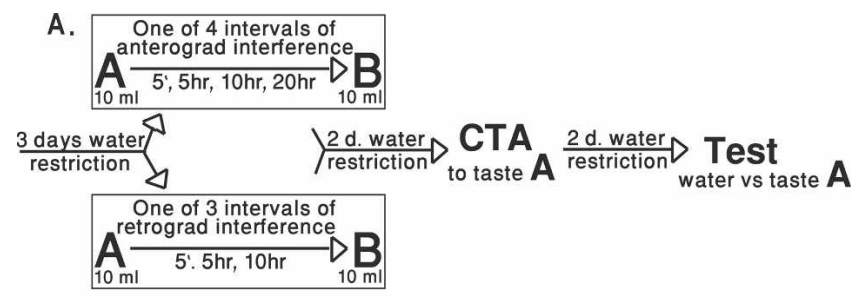

B.



C.

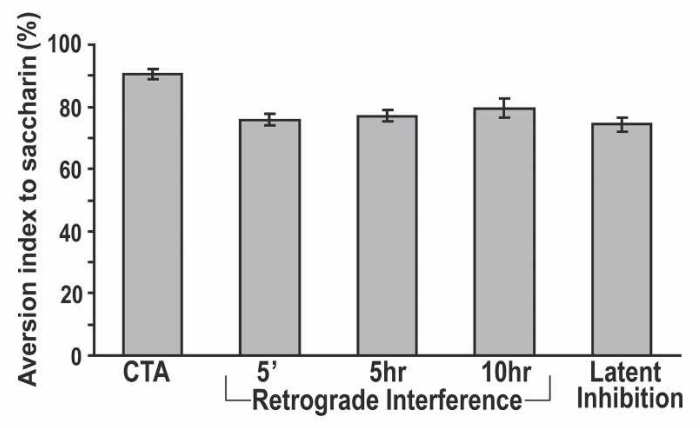

D.

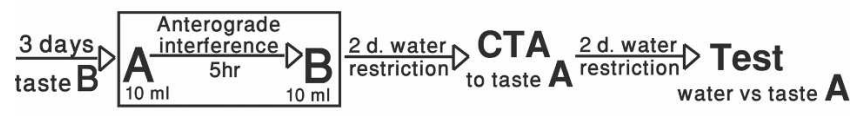

E.



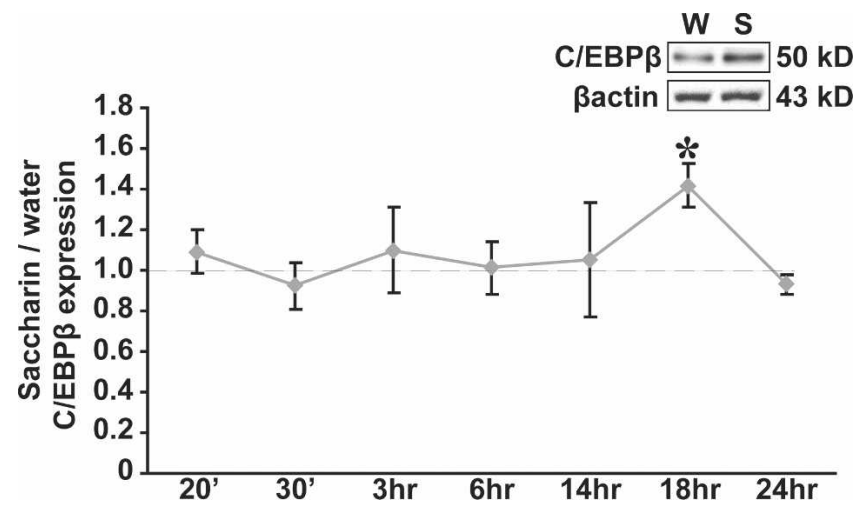

Figure 2. Novel taste learning induces $C / E B P \beta$ 's protein expression in the insular cortex $18 \mathrm{~h}$ following learning. At different time points after consumption of $>10 \mathrm{~mL}$ of $0.1 \%$ saccharin (test group), or water (control group), the insular cortex was removed and subjected to Western blot analysis. The graph depicts the ratio of $C / E B P \beta$ protein expression divided by $\beta$ actin's expression values (C/EBP $\beta$ vs. $\beta$ actin) between test group (saccharin drinkers) and control group (water drinkers), at different time points after drinking, in the insular cortex. No difference was obtained in the expression level of $\beta$ actin at any time point (data is not presented). 2 $\min : 0.999 \pm 0.114, n=7 ; 20 \min : 0.954 \pm 0.119, n=7 ; 30 \mathrm{~min}:$ $1.018 \pm 0.119, n=6 ; 3$ h: $0.980 \pm 0.124, n=15 ; 6$ h: $0.938 \pm 0.128$ $n=6 ; 14$ h: $1.053 \pm 0.131, n=10 ; 18$ h: $1.417 \pm 0.128, n=5 ; 24$ h: $0.932 \pm 0.050, n=8$. A representative immunoblot of C/EBP $\beta$ and $\beta$ actin $18 \mathrm{~h}$ following drinking consumption is displayed on the top right corner. *Saccharin group in comparison to the water group, $P<0.01$.

following input that was similar in modality but different in direction or scale.

To define the time frame of the consolidation phase as measured by interference with a second taste input, we presented the rats in the LI paradigm with two taste inputs, separated by different time intervals, in the LI paradigm $(5,10,20 \mathrm{~h})$ (Fig. 1). To

Figure 1. A consecutive novel taste induces retrograde but not anterograde amnesia, in a time interval of $>5 \mathrm{~h}$. (A) A diagram, presenting the anterograde and retrograde interference protocols. During WD days, the rats receive $20 \mathrm{~mL}$ of water. At day four, the rats are introduced to $10 \mathrm{~mL}$ of taste A. On a certain interval after or before ( $5 \mathrm{~min}$, or $5,10,20 \mathrm{~h}$ ), the rats are introduced to $10 \mathrm{~mL}$ of taste $B$. Three days later, aversion to taste $\mathrm{A}$ is conditioned, using $\mathrm{LiCl}$. (B) Novel taste induces retrograde amnesia. An input of $10 \mathrm{~mL} \mathrm{NaCl} 0.3 \%$ was given at different time intervals after the pre exposure to $10 \mathrm{~mL}$ of saccharin $0.1 \%$.The time intervals were $5^{\prime}$, $5 \mathrm{~h}, 10 \mathrm{~h}$, and $20 \mathrm{~h}$. The memory to $10 \mathrm{~mL}$ of saccharin was impaired when $10 \mathrm{~mL}$ of $\mathrm{NaCl} 0.3 \%$ was given 5', $5 \mathrm{~h}$, and $10 \mathrm{~h}$ after it. The memory for $10 \mathrm{~mL}$ of saccharin was not impaired when the interval between two inputs was $20 \mathrm{~h}$. CTA: $90.4 \pm 1.7, n=13 ; 5^{\prime}: 93.3 \pm 1.7$, $n=8 ; 5$ h: $90.0 \pm 2.2, n=13 ; 10$ h: $85.6 \pm 2.4, n=9 ; 20$ h: $80.8 \pm 3.8$, $n=7$; LI: $74.4 \pm 2.3, n=16$. ${ }^{*}$ Different from latent inhibition (LI) group. (C) Novel taste does not induce anerograde amnesia. An input of $10 \mathrm{~mL}$ of $\mathrm{NaCl}$ $0.3 \%$ is given at different time intervals $\left(5^{\prime}, 5 \mathrm{~h}\right.$, and $10 \mathrm{~h}$ ) before the pre-exposure to $10 \mathrm{~mL}$ of saccharin $0.1 \%$. It does not affect the aversion level, in comparison to LI $10 \mathrm{~mL}$. Values are mean \pm SEM; ${ }^{*} P<0.05(n \geq 8$ animals). CTA: $90.4 \pm 1.7, n=13 ; 5^{\prime}: 75.9 \pm 1.8, n=9 ; 5$ h: $77.1 \pm 1.9$, $n=8 ; 10$ h: $79.5 \pm 3.0, n=4$; LI: $74.4 \pm 2.3, n=16$. (D) A diagram, presenting an anterograde interference protocol, in which taste $B$ is not a novel taste. Rats are introduced to taste $B$ during the first $3 \mathrm{~d}$. At day four, the rats are introduced to $10 \mathrm{~mL}$ of taste $A$. Five hours later, $10 \mathrm{~mL}$ of taste $B$ is consumed. Three days later, aversion to taste $\mathrm{A}$ is conditioned, using $\mathrm{LiCl}$. $(E)$ Known taste does not induce retrograde amnesia. Among rats that have (already) been introduced to $\mathrm{NaCl} 0.3 \%, 10 \mathrm{~mL}$ of this solution does not create interference. The consolidation of $10 \mathrm{~mL}$ of saccharin $0.1 \%$ is not affected when $10 \mathrm{~mL}$ of familiar $\mathrm{NaCl} 0.3 \%$ is consumed $5 \mathrm{~h}$ later (5-h novel taste, 5-h familiar taste). The aversion level is not different from LI, in comparison to 5 -h interference, when $\mathrm{NaCl} 0.3 \%$ is not familiar. CTA: $90.4 \pm 1.7, n=13 ; 5$-h novel taste: $90.0 \pm 2.2, n=13 ; 5$-h familiar taste: $68.3 \pm 4.3, n=5$; LI: $74.4 \pm 2.3, n=16$. *Different from the novel taste, 5-h anterograde interference group. 
A.



B.

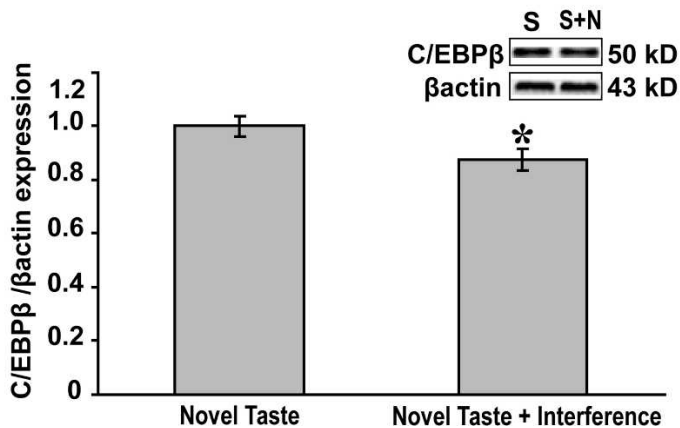

Figure 3. A novel taste does not induce $\mathrm{C} / \mathrm{EBP} \beta$ 's expression if followed by a different novel taste. $(A) \mathrm{A}$ diagram, presenting the interference protocol with measurement of $C / E B P \beta$ in the insular cortex. Both test and control groups consumed $10 \mathrm{~mL}$ of saccharin $0.1 \%$. Four hours later, the test group consumed $10 \mathrm{~mL} \mathrm{NaCl} 0.3 \%$, while the control group consumed $10 \mathrm{~mL}$ of water. Eighteen hours following saccharin consumption, the insular cortex was removed and subjected to Western blot analysis. (B) Novel taste does not modulate the expression of $C / E B P \beta$, if a different novel taste is consumed $4 \mathrm{~h}$ following it. The graph depicts the ratio of $\mathrm{C} / \mathrm{EBP} \beta$ protein expression divided by $\beta$ actin expression values. The ratio (C/EBP $\beta$ vs. $\beta$ actin) in test group is lower than in control group $(0.877 \pm 0.040 n=9$ in test group; $1.001 \pm 0.038 n=10$ in control group; $t$-test: $\left.t_{(17)}=-2.230, P<0.05\right)$. A representative immunoblot of $\mathrm{C} / \mathrm{EBP} \beta$ and $\beta$ actin is attached at top right corner.

our surprise, the time frame for memory interference lasted for at least $10 \mathrm{~h}$ (Fig. 1B). However, the directionality of interference was maintained and the second taste memory was not disrupted, similar to the result obtained with the 5-min interval (Fig. 1C).

It is possible that the prolonged consolidation time for novel taste information is unique to the taste system in the same way that association between novel taste and malaise tolerates an unusually long time (Rosenblum et al. 1993).

Recent studies in the taste system, as well as in other learning paradigms, have suggested that retrieving information has a dimension of relearning (Berman and Dudai 2001; Eisenberg et al. 2003). We thus compared between the ability of learning and the ability of retrieving/relearning to interfere with the process of taste memory consolidation. Indeed, when the secondinterfering taste input was a familiar one (Fig. 1D), no reduction in the consolidation was observed (Fig. 1D,E). These results demonstrated that the mechanisms for learning novel information differ from those for relearning known information. Moreover, they demonstrated that unlike retrieving known information, learning new unimodal information occupies the brain in such a way that only one bit of new information can be consolidated over a long period of time.

From a biochemical perspective, no correlation was reported so far between novel taste learning and gene induction in the insular cortex. However, in other learning paradigms and for longer time frames, it was reported that C/EBP $\beta$ was induced in the hippocampus 9-28 $\mathrm{h}$ following avoidance learning (Taubenfeld et al. 2001). We thus examined the time dependency of $\mathrm{C} / \mathrm{EBP} \beta$ 's expression in the taste cortex at different time intervals following novel taste input. C/EBP $\beta$ 's expression was induced 18 $\mathrm{h}$ following consumption of novel taste and returned to control level at $24 \mathrm{~h}$ following it (Fig. 2). This is the first demonstration of correlative modulation in gene expression in the taste cortex following novel taste learning.
Altogether, one can conclude that taste memory consolidation has a time frame that stretches from minutes to many hours following learning. In addition, unimodal novel taste input affects the consolidation of former novel taste and a correlative gene induction in the taste cortex.

\section{Acknowledgments}

This work was supported by ISF and Psychobiology grants for KR.

\section{References}

Alberini, C.M. 1999. Genes to remember. J. Exp. Biol. 202: 2887-2891.

Arwas, S., Rolnick, A., and Lubow, R.E. 1989. Conditioned taste aversion in humans using motion-induced sickness as the US. Behav. Res. Ther. 27: 295-301.

Belelovsky, K., Elkobi, A., Kaphzan, H., Nairn, A.C., and Rosenblum, K. 2005. A molecular switch for translational control in taste memory consolidation. Eur. J. Neurosci. 22: 2560-2568.

Berman, D.E. and Dudai, Y. 2001. Memory extinction, learning anew, and learning the new: Dissociations in the molecular machinery of learning in cortex. Science 291: 2417-2419.

Berman, D.E., Hazvi, S., Rosenblum, K., Seger, R., and Dudai, Y. 1998. Specific and differential activation of mitogen-activated protein kinase cascades by unfamiliar taste in the insular cortex of the behaving rat. J. Neurosci. 18: 10037-10044.

Davis, H.P. and Squire, L.R. 1984. Protein synthesis and memory: A review. Psychol. Bull. 96: 518-559.

Dudai, Y. 2004. The neurobiology of consolidations, or, how stable is the engram? Annu. Rev. Psychol. 55: 51-86.

Eisenberg, M., Kobilo, T., Berman, D.E., and Dudai, Y. 2003. Stability of retrieved memory: Inverse correlation with trace dominance. Science 301: 1102-1104.

Ferreira, G., Gutierrez, R., De La Cruz, V., and Bermudez-Rattoni, F. 2002. Differential involvement of cortical muscarinic and NMDA receptors in short- and long-term taste aversion memory. Eur. J. Neurosci. 16: 1139-1145.

Flook, J.P. and McGonigle, B.O. 1977. Serial adaptation to conflicting prismatic rearrangement effects in monkey and man. Perception 6: 15-29.

Gallo, M., Bielavska, E., Roldan, G., and Bures, J. 1998. Tetrodotoxin inactivation of the gustatory cortex disrupts the effect of the $\mathrm{N}$-methyl-D-aspartate antagonist ketamine on latent inhibition of conditioned taste aversion in rats. Neurosci. Lett. 240: 61-64.

Goedert, J. 2002. Speech recognition technology gives voice to clinical data. Health Data Manag. 10: 30-32, 34, 36 passim.

Houpt, T.A. and Berlin, R. 1999. Rapid, labile, and protein synthesis-independent short-term memory in conditioned taste aversion. Learn. Mem. 6: 37-46.

Meiri, N. and Rosenblum, K. 1998. Lateral ventricle injection of the protein synthesis inhibitor anisomycin impairs long-term memory in a spatial memory task. Brain Res. 789: 48-55.

Miranda, M.I. and McGaugh, J.L. 2004. Enhancement of inhibitory avoidance and conditioned taste aversion memory with insular cortex infusions of 8-Br-cAMP: Involvement of the basolateral amygdala. Learn. Mem. 11: 312-317.

Miranda, M.I., Ramirez-Lugo, L., and Bermudez-Rattoni, F. 2000. Cortical cholinergic activity is related to the novelty of the stimulus. Brain Res. 882: 230-235.

Rosenblum, K., Meiri, N., and Dudai, Y. 1993. Taste memory: The role of protein synthesis in gustatory cortex. Behav. Neural Biol. 59: $49-56$.

Rosenblum, K., Schul, R, Meiri, N., Hadari, Y.R, Zick, Y., and Dudai, Y. 1995. Modulation of protein tyrosine phosphorylation in rat insular cortex after conditioned taste aversion training. Proc. Natl. Acad. Sci. 92: $1157-1161$.

Rosenblum, K., Berman, D.E., Hazvi, S., and Dudai, Y. 1996. Carbachol mimics effects of sensory input on tyrosine phosphorylation in cortex. Neuroreport 7: 1401-1404.

Rosenblum, K., Berman, D.E., Hazvi, S., Lamprecht, R., and Dudai, Y. 1997. NMDA receptor and the tyrosine phosphorylation of its $2 \mathrm{~B}$ subunit in taste learning in the rat insular cortex. J. Neurosci. 17: $5129-5135$.

Taubenfeld, S.M., Milekic, M.H., Monti, B., and Alberini, C.M. 2001. The consolidation of new but not reactivated memory requires hippocampal C/EBPß. Nat. Neurosci. 4: 813-818.

Wixted, J.T. 2004. The psychology and neuroscience of forgetting. Annu. Rev. Psychol. 55: 235-269.

Received February 20, 2006; accepted in revised form June 13, 2006. 


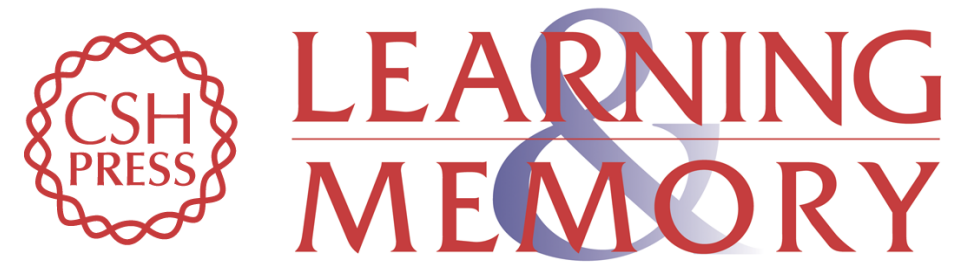

\section{Behavioral interference and C/EBP $\beta$ expression in the insular-cortex reveal a prolonged time period for taste memory consolidation}

Maayan Merhav, Shelly Kuulmann-Vander, Alina Elkobi, et al.

Learn. Mem. 2006, 13:

Access the most recent version at doi:10.1101//m.282406

References This article cites 22 articles, 8 of which can be accessed free at: http://learnmem.cshlp.org/content/13/5/571.full.html\#ref-list-1

License

Email Alerting

Receive free email alerts when new articles cite this article - sign up in the box at the Service top right corner of the article or click here. 